\title{
Perancangan Self-Assessment ISO 22000:2018 pada PT X dengan Metode Baldrige Scoring
}

\author{
Jeremy Kusuma $^{1}$, Lie Angela Sugiarto ${ }^{2}$, Jani Rahardjo ${ }^{3 *}$ \\ 1,2,3Program Studi Teknik Industri, Universitas Kristen Petra, Surabaya, Indonesia
}

(*jani@petra.ac.id)

\begin{abstract}
Abstrak - Era globalisasi menyebabkan perusahaan harus meningkatkan kemampuannya untuk bersaing. Penerapan standar merupakan salah satu cara untuk tetap meningkatkan kualitas serta memproduksi bahan pangan yang lebih bermutu. Standar yang tepat untuk diterapkan pada perusahaan yang bergerak di industri pangan adalah ISO 22000:2018. ISO 22000:2018 merupakan sebuah standar yang mengatur tentang sistem manajemen keamanan pangan. PT X merupakan perusahaan yang bergerak di industri pangan frozen food di Surabaya. Penelitian ini dilakukan dengan merancang pertanyaan self-assessment yang sesuai dengan klausa 4 hingga klausa 10 pada sistem manajemen keamanan pangan ISO 22000:2018. Pemenuhan dokumen yang berkaitan dengan sertifikasi ISO 22000:2018 diperlukan untuk melakukan audit internal melalui self-assessment dan dilanjutkan oleh audit eksternal oleh auditor dari pihak ketiga. Audit internal dilakukan dengan menggunakan metode self assessment dengan merancangkan pertanyaan. Pertanyaan tersebut didapatkan dari hasil identifikasi pada klausul. Kemudian penilaian dilakukan untuk setiap pertanyaan dengan metode baldrige scoring berdasarkan faktor dimensi proses yaitu pendekatan, penyebarluasan, pembelajaran, integrasi. Hasil penelitian ini akan membantu perusahaan selangkah lebih dekat dengan penerapan ISO dengan merencanakan butir-butir pertanyaan self-assessment yang sesuai dengan klausul 4 hingga klausul 10 pada ISO 22000:2018 dengan kategori penilaian menggunakan metode baldrige scoring.
\end{abstract}

Kata kunci: Baldrige scoring; food safety; ISO 22000:2018

\section{PENDAHULUAN}

Persaingan di era globalisasi ini membuat banyak perusahaan terus melakukan perbaikan agar dapat bersaing dengan perusahaan lainnya. Hal ini dilakukan oleh perusahaan yang bergerak di berbagai bidang, salah satunya adalah perusahaan yang bergerak di industri pangan. Perbaikan terus dilakukan dengan cara menerapkan sebuah standar yaitu penerapan ISO 22000 tentang sistem manajemen keamanan pangan. Keamanan pangan sendiri merupakan hal yang penting bagi kesehatan konsumennya. Masyarakat yang menjadi konsumen dari produk perusahaan akan mengkonsumsi makanan dan minuman yang lebih bermutu sehingga kesehatannya lebih terjaga terlebih di era pandemi Covid-19. Perusahaan juga dapat berkontribusi terhadap program kesehatan yang sedang digalakkan oleh pemerintahan melalui diterapkannya ISO 22000.

PT X merupakan perusahaan di industri pangan frozen food di Surabaya, sehingga perusahaan ini sangat membutuhkan penerapan sistem manajemen keamanan pangan. Mengingat hal tersebut, standarisasi sistem manajemen keamanan pangan seperti ISO 22000 sangat diperlukan oleh perusahaan. Namun, PT X sendiri belum memiliki sertifikasi ISO 22000:2018, sehingga diperlukannya pemenuhan dokumen-dokumen yang diperlukan untuk kebutuhan sertifikasi dengan audit internal melalui self assessment. Self assessment akan mempermudah perusahaan melengkapi dokumen yang diperlukan, setelah itu dokumen dapat diimplementasikan dengan melakukan sosialisasi kepada pekerja dan dilakukan tinjauan ulang oleh manajemen. Setelah itu, audit eksternal oleh pihak ketiga dapat dilakukan untuk mendapatkan sertifikasi ISO 22000:2018.

Audit internal biasanya dilaksanakan dengan melakukan audit antar departemen. Selain itu, cara lain yang dapat dilakukan untuk audit internal dengan self assessment untuk setiap departemen. Hasil penilaian dari self assessment harus dipastikan sesuai atau akurat, sehingga akan memudahkan PT X untuk mendapatkan sertifikasi ISO 22000:2018. Tujuan dari penelitian ini adalah merancangkan pertanyaan dan penilaian yang diperlukan untuk self assessment PT X menggunakan metode baldrige scoring. Harapannya dengan melakukan perancangan self assessment akan mengetahui sejauh mana kesiapan PT X dalam mempersiapkan penerapan ISO 22000:2018. 


\section{STUDI LITERATUR}

\section{A. Sistem Manajemen Keamanan Pangan}

Sistem manajemen keamanan pangan adalah hubungan antara berbagai macam unsur yang saling berhubungan yang berguna untuk memastikan bahwa makanan yang akan dikonsumsi tidak menyebabkan efek dan merugikan kesehatan manusia (Singh, 2015). Unsur tersebut meliputi program, perencanaan, kebijakan, prosedur, praktik, proses, tujuan, sasaran, metode, kontrol, tanggung jawab, hubungan, dokumen dan sumber daya. Penerapan ISO 22000 ini menggabungkan dan melengkapi ISO 9001, standar sistem manajemen mutu, dan HACCP (Hazard Analysis Critical Control Points), serta pendekatan preventif untuk keamanan pangan (Mengenal 4 Elemen Utama ISO 22000:2018, 2020). Dalam rantai produksi pangan diperlukan HACCP (Hazard Analysis Critical Control Points) atau HARPC (Hazard Analysis and Risk-Based Preventive Controls) untuk mengendalikan bahaya dalam produksi pangan selain memiliki sistem manajemen keamanan pangan (Borda et al., 2021). Perusahaan di bidang pangan memiliki beberapa alasan dalam penerapan sistem manajemen pangan. Hal ini didukung oleh beberapa studi yang dilakukan pada berbagai perusahaan yang tersebar di banyak sektor. Salah satu alasan yang merupakan motivasi menggunakan sistem manajemen keamanan pangan di beberapa perusahaan ditemukan pada sektor yang bergerak di industri pangan di Inggris oleh Henson dan Holt (2000). Alasan yang ditemukan adalah dalam rangka memenuhi kewajiban perusahaan untuk mengikuti peraturan di negaranya serta sebagai sebuah langkah bagi perusahaan untuk memenuhi permintaan dari pelanggannya. Penemuan selanjutnya ditemukan di negara China melalui penelitian yang dilakukan oleh Jin, et al. (2008).

\section{B. ISO 22000:2018}

ISO 22000:2018 merupakan sebuah standar yang memungkinkan sebuah organisasi yang terlibat secara langsung maupun tidak langsung di bidang pangan untuk mengaplikasikan sistem manajemen keamanan pangan di dalam perusahaan tersebut ("ISO 22000:2018", 2021). ISO 22000:2018 adalah hasil perubahan dari ISO 22000:2005 yang mengalami beberapa revisi terhadap klausul-klausul yang telah ada sebelumnya. ISO 22000:2018 memiliki prinsip-prinsip tertentu seperti komunikasi yang interaktif, manajemen sistem, prerequisite programs, pengendalian bahaya, fokus pada pelanggan, kepemimpinan, keterlibatan manusia, pendekatan proses, perbaikan, pengambilan keputusan berdasarkan bukti, serta manajemen relasi ("ISO 22000:2018", 2021).

\section{Baldrige Scoring System}

Baldrige scoring system merupakan sebuah metode penilaian yang digunakan dalam evaluasi manajemen kualitas di Amerika Serikat, yaitu Malcolm Baldrige National Quality Award (MBNQA). Baldrige scoring system terbagi menjadi dua yaitu penilaian terhadap proses dan hasil. Penilaian memiliki beberapa kriteria yaitu terfokus pada hasil, tidak mengatur, dapat disesuaikan, keselarasan perspektif kesisteman, dan mendukung diagnosa berbasis sasaran (Indonesian Quality Award Foundation, 2013). Pendekatan untuk penerapan kriteria penilaian Malcolm Baldrige adalah approach (pendekatan), deployment (penyebarluasan), learning (pembelajaran), dan integration (integrasi) (Indonesian Quality Award Foundation, 2013). Faktor penilaian approach (pendekatan) merujuk pada pendekatan dengan adanya perencanaan yang dilakukan. Deployment (penyebarluasan) merujuk pada perencanaan yang sudah dilakukan dan dilakukan pengembangan, namun belum dilakukan penerapan. Learning (pembelajaran) merujuk pada perencanaan dan proses penerapan telah dilaksanakan. Integration (integrasi) merujuk pada perencanaan, penerapan proses telah dilakukan dengan baik dan adanya evaluasi atas tindakan. Baldrige scoring system digunakan karena memiliki keterkaitan dengan adanya sebuah standar untuk penilaian terhadap pencapaian yang telah dilakukan oleh perusahaan dalam hal memenuhi klausul-klausul pada ISO 22000:2018.

\section{Self Assessment}

Self assessment atau penilaian diri merupakan tindakan atau proses untuk menganalisa dan mengevaluasi seseorang ("Self-assessment"). Self assessment membuat organisasi mengidentifikasi dan mendokumentasikan nilai ini, faktor pendukung kesuksesan, dan lain-lain (Gaspersz, 2002). Menurut Tillema (2010), self assessment merupakan sebuah peninjauan ulang dan pemberian kritik terhadap progres kinerja seseorang 
dalam periode waktu tertentu. Self assessment dapat membantu perusahaan dalam mengevaluasi hasil kinerja perusahaan apakah sudah sesuai dengan tujuan atau sasaran yang ingin dicapai oleh perusahaan. Hasil self assessment dapat memberikan gambaran kondisi perusahaan, sehingga perusahaan akan lebih mudah dalam menentukan langkah yang harus diambil, baik langkah perbaikan atau pengembangan berkelanjutan.

\section{METODOLOGI}

Dalam melakukan perancangan pertanyaan self assessment diperlukan tahapan untuk melakukan penelitian. Gambar 1 merupakan metodologi penelitian ini:

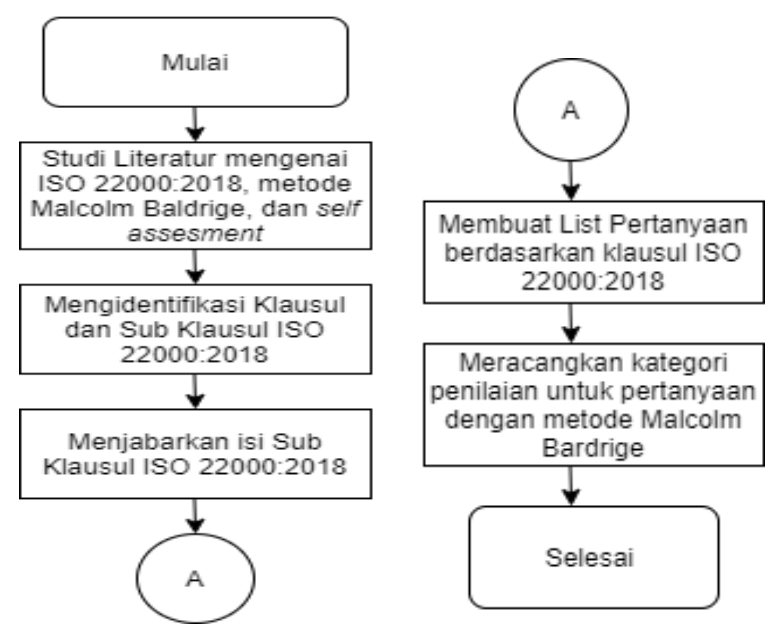

Gambar 1. Metodologi penelitian

Langkah pertama yang dilakukan adalah melakukan studi literatur mengenai klausul-klausul ISO 22000:2018, metode Baldrige Scoring, dan self assessment. Studi literatur ini dilakukan dengan mencari beberapa referensi konsep dasar teori hal-hal yang akan dibahas pada jurnal. Referensi ini akan digunakan dalam menunjang penelitian yang akan dilakukan. Langkah kedua adalah mengidentifikasi klausul dan sub klausul ISO 22000:2018. Langkah ketiga adalah menjabarkan isi dari sub klausul ISO 22000:2018. Langkah keempat adalah membuat daftar pertanyaan yang akan digunakan untuk melakukan self assessment. Daftar pertanyaan yang ada akan disesuaikan dengan hasil identifikasi yang dilakukan pada klausul 4-10 ISO 22000:2018. Langkah terakhir adalah membuat kategori penilaian untuk pertanyaan self assessment berdasarkan metode baldrige scoring. Kategori penilaian akan ditentukan berdasarkan faktor kriteria baldrige scoring system dimensi proses yaitu pendekatan, penyebarluasan, pembelajaran, integrasi.

\section{HASIL DAN DISKUSI}

ISO 22000:2018 merupakan sebuah standar yang dijalankan dengan prinsip Plan-Do-Check-Act (PDCA). Hal tersebut tercermin dalam 10 klausul yang terdapat dalam ISO 22000:2018. Klausul 4-7 merupakan klausul dengan tahap plan, klausul 8 merupakan tahap do, klausul 9 merupakan tahap check, klausul 10 merupakan tahap act. Penelitian ini akan membahas mengenai perancangan pertanyaan self assessment dan kategori penilaian untuk pertanyaan self assessment berdasarkan metode baldrige scoring pada klausul $4-10$. Hasil identifikasi ISO 22000: 2018 yang akan dibahas pada penelitian ini akan difokuskan pada klausul 8 karena perusahaan akan diminta merencanakan, menerapkan, mengendalikan proses yang diperlukan dan bahaya dalam sistem. Berikut ini merupakan hasil identifikasi klausul 8:

- Klausul 8

Klausul 8 membahas mengenai operasional perusahaan dimana perusahaan harus melakukan perencanaan, penerapan, dan pengendalian terhadap proses yang diperlukan sebagai prasyarat penerapan tindakan. Perusahaan juga diminta untuk mempersiapkan dan tanggap darurat serta pengendalian bahaya pada sistem manajemen keamanan pangan, salah satunya dengan memahami Hazard Analysis Critical Control Points (HACCP). Klausul 8 terdiri atas 9 sub klausul, yaitu: 
a. 8.1 Perencanaan dan pengendalian operasional

b. 8.2 Program Prasyarat (PRP)

c. 8.3 Sistem keterlacakan

d. 8.4 Kesiagaan dan tanggap darurat

e. 8.5 Pengendalian bahaya

f. 8.6 Memperbaharui informasi PRP dan rencana pengendalian bahaya

g. 8.7 Pengendalian, pemantauan, dan pengukuran

h. 8.8 Verifikasi PRP dan rencana pengendalian bahaya

i. 8.9 Pengendalian kesesuaian produk dan proses

Hasil identifikasi yang telah dilakukan pada klausul ISO 22000: 2018 akan membantu menghasilkan pertanyaan yang dapat digunakan saat melakukan self assessment. Tabel 1 merupakan pertanyaan self assessment telah dibagi berdasarkan sub-sub klausul 8. Setiap sub klausul memiliki pertanyaan akan membantu perusahaan memastikan bahwa prasyarat yang diperlukan untuk sertifikasi ISO.

Tabel 1

Pertanyaan Self Assessment Klausul 8

\begin{tabular}{|c|c|}
\hline SUB KLAUSUL & PERTANYAAN \\
\hline \multirow[b]{2}{*}{8.1 (Operational Planning \& Control) } & $\begin{array}{l}\text { Apakah perusahaan telah merencanakan, mengimplementasikan, mengendalikan, } \\
\text { memelihara dan memperbaharui persyaratan produk? }\end{array}$ \\
\hline & $\begin{array}{l}\text { Apakah perusahaan telah mengendalikan jika ada perubahan rancangan dan meninjau } \\
\text { konsekuensi yang akan terjadi jika melakukan perubahan untuk meminimalkan efek yang } \\
\text { akan terjadi? }\end{array}$ \\
\hline 8.2 (Pre Requisite Program) & $\begin{array}{l}\text { Apakah perusahaan telah menetapkan dan menerapkan PRP untuk memfasilitasi } \\
\text { kontaminasi terjadi pada produk yang diproduksi? }\end{array}$ \\
\hline 8.3 (Traceability System) & $\begin{array}{l}\text { Apakah perusahaan telah melakukan identifikasi/verifikasi mengenai produk yang belum } \\
\text { jadi hingga sudah jadi? }\end{array}$ \\
\hline 8.4 (Emergency Preparedness \& Response) & $\begin{array}{l}\text { Apakah perusahaan telah melakukan penetapan tim untuk merancangkan prosedur jika } \\
\text { terjadi kejadian darurat, dan melakukan simulasi agar pengendalian produk tetap terjaga } \\
\text { walaupun situasi darurat? }\end{array}$ \\
\hline \multirow{3}{*}{8.5 (Hazard Control) } & $\begin{array}{l}\text { Apakah perusahaan telah melakukan pengendalian bahaya yang signifikan dalam bahan } \\
\text { baku/bahan kemasan dari produk? }\end{array}$ \\
\hline & Apakah perusahaan telah merencanakan tindakan pencegahan terhadap risiko bahaya? \\
\hline & $\begin{array}{l}\text { Apakah perusahaan telah melakukan dokumentasi mengenai informasi pengendalian } \\
\text { bahaya dan rancangan pencegahan yang akan dilakukan? }\end{array}$ \\
\hline \multirow{3}{*}{$\begin{array}{l}8.6 \text { (Updating the Information Specifying the PRPS } \\
\text { and the Hazard Control Plan) }\end{array}$} & $\begin{array}{l}\text { Apakah perusahaan telah melakukan pembaharuan informasi mengenai PRP dan } \\
\text { perencanaan hazard control? }\end{array}$ \\
\hline & $\begin{array}{l}\text { Apakah perusahaan telah melakukan pembaharuan informasi mengenai penggunaan yang } \\
\text { dimaksudkan dari produk? }\end{array}$ \\
\hline & $\begin{array}{l}\text { Apakah perusahaan telah melakukan pembaharuan informasi mengenai peta diagram alir } \\
\text { dan deskripsi dari proses beserta lingkungan proses produksi? }\end{array}$ \\
\hline \multirow{3}{*}{8.7 (Control of Monitoring and Measuring) } & $\begin{array}{l}\text { Apakah perusahaan telah melakukan kalibrasi atau verifikasi terhadap alat serta metode } \\
\text { pemantauan dan pengukuran secara berkala? }\end{array}$ \\
\hline & $\begin{array}{l}\text { Apakah perusahaan telah melakukan penyesuaian yang sesuai terhadap alat serta metode } \\
\text { pemantauan dan pengukuran? telah melakukan pencatatan? }\end{array}$ \\
\hline & $\begin{array}{l}\text { Apakah perusahaan telah memastikan bahwa alat serta metode pemantauan dan } \\
\text { pengukuran terlindungi dari kerusakan? }\end{array}$ \\
\hline \multirow{3}{*}{$\begin{array}{l}8.8 \text { (Verification Related to PRPs and the Hazard } \\
\text { Control Plan) }\end{array}$} & Apakah perusahaan telah menetapkan, menerapkan, dan memelihara kegiatan verifikasi? \\
\hline & $\begin{array}{l}\text { Apakah kegiatan verifikasi telah memastikan PRPs dan rencana pengendalian bahaya, dan } \\
\text { tindakan lain yang ditentukan perusahaan telah dilaksanakan dan efektif? }\end{array}$ \\
\hline & $\begin{array}{l}\text { Apakah organisasi telah menyimpan hasil verifikasi dalam bentuk dokumentasi? Apakah } \\
\text { sudah dikomunikasikan ke tiap departemen? }\end{array}$ \\
\hline \multirow{2}{*}{$\begin{array}{l}\text { 8.9. (Control of Products and Process } \\
\text { Nonconformities) }\end{array}$} & $\begin{array}{l}\text { Apakah perusahaan memiliki prosedur untuk melakukan identifikasi terhadap } \\
\text { pengendalian produk yang tidak sesuai dengan persyaratan? }\end{array}$ \\
\hline & $\begin{array}{l}\text { Apakah tindakan yang dilakukan perusahaan jika produk yang tidak sesuai sudah berada } \\
\text { diluar organisasi? }\end{array}$ \\
\hline
\end{tabular}


Perancangan kategori penilaian self assessment dilakukan berdasarkan dari penilaian faktor baldrige scoring. Penilaian skor self assessment pada penelitian ini memiliki skor 1 hingga 5. Skor 1 dengan baldrige scoring $0-5 \%$ menggambarkan bahwa belum adanya pendekatan yang dilakukan perusahaan untuk memenuhi prasyarat klausul ISO 22000:2018. Skor 2 dengan baldrige scoring 10-20\% atau 30-45\% menggambarkan tahapan approach bahwa adanya pendekatan yang dilakukan perusahaan, namun belum merancangkan dan menerapkan untuk memenuhi prasyarat klausul ISO 22000:2018. Skor 3 dengan baldrige scoring 50-65\% menggambarkan tahapan deployment bahwa adanya pendekatan dan perancangan yang dilakukan perusahaan, namun belum menerapkan untuk memenuhi prasyarat klausul ISO 22000:2018. Skor 4 dengan baldrige scoring 70-85\% menggambarkan tahapan learning bahwa adanya pendekatan, perancangan, dan penerapan telah dilakukan perusahaan untuk memenuhi prasyarat klausul ISO 22000:2018. Skor 5 dengan baldrige scoring 90-100\% menggambarkan tahapan integration bahwa adanya pendekatan, perancangan, dan penerapan telah dilakukan perusahaan untuk memenuhi prasyarat klausul ISO 22000:2018, selain itu telah dilakukan evaluasi secara rutin. Tabel 2 merupakan kategori penilaian skor self assessment.

Tabel 2

Kategori penilaian skor self assessment

\begin{tabular}{|c|c|c|}
\hline Skor & Baldrige Scoring & Keterangan \\
\hline 1 & $0-5 \%$ & $\begin{array}{l}\text { Perusahaan belum merencanakan, merancangkan, menentukan, membuat, dan } \\
\text { menerapkan prosedur. }\end{array}$ \\
\hline 2 & $\begin{array}{c}10-20 \% \text { atau } \\
30-45 \% \\
(\text { Approach })\end{array}$ & $\begin{array}{l}\text { Perusahaan sudah melakukan perencanaan, namun belum melakukan perancangan dan } \\
\text { penerapan prosedur. }\end{array}$ \\
\hline 3 & $\begin{array}{c}50-65 \% \\
(\text { Deployment })\end{array}$ & $\begin{array}{l}\text { Perusahaan sudah merancangkan serta membuat prosedur dan/atau dokumentasi namun } \\
\text { belum melakukan penerapan dan/atau dokumentasi. }\end{array}$ \\
\hline 4 & $\begin{array}{l}70-85 \% \\
(\text { Learning) }\end{array}$ & $\begin{array}{l}\text { Perusahaan sudah merancangkan, menentukan, membuat, dan menerapkan prosedur } \\
\text { dan/atau dokumentasi. }\end{array}$ \\
\hline 5 & $\begin{array}{c}90-100 \% \\
\text { (Integration) }\end{array}$ & $\begin{array}{l}\text { Perusahaan sudah merancangkan, menentukan, membuat, dan menerapkan prosedur } \\
\text { dan/atau dokumentasi, serta telah dilakukan evaluasi dan dikendalikan. }\end{array}$ \\
\hline
\end{tabular}

Kategori skor 1 pada penilaian self assessment ditujukan apabila perusahaan belum merancangkan, menentukan, membuat, dan menerapkan prosedur dan/atau dokumentasi. Kategori skor 2 pada penilaian self assessment ditujukan apabila perusahaan sudah melakukan perencanaan, namun belum melakukan perancangan dan penerapan prosedur dan/atau dokumentasi. Kategori skor 3 pada penilaian self assessment ditujukan apabila perusahaan sudah merancangkan serta membuat prosedur dan/atau dokumentasi namun belum melakukan penerapan. Kategori skor 4 pada penilaian self assessment ditujukan apabila perusahaan sudah merancangkan, menentukan, membuat, dan menerapkan prosedur dan/atau dokumentasi. Kategori skor 5 pada penilaian self assessment ditujukan apabila perusahaan sudah merancangkan, menentukan, membuat, dan menerapkan prosedur dan/atau dokumentasi, serta telah dilakukan evaluasi dan dikendalikan.

\section{KESIMPULAN}

Adanya perancangan self assessment dengan membantu membuat pertanyaan yang diperlukan diharapkan dapat membantu PT X untuk melakukan pengecekan guna mempersiapkan kebutuhan dokumen yang diperlukan sebagai prasyarat sertifikasi ISO 22000:2018. Selain itu, rancangan ini juga akan membantu PT X dalam mengambil tindakan perbaikan untuk memenuhi prasyarat sertifikasi ISO 22000:2018 sebelum dilakukan audit oleh auditor. Self assessment dilakukan dengan menggunakan metode baldrige scoring yang merupakan metode yang sesuai untuk digunakan dalam self assessment dalam rangka memperoleh sertifikasi ISO 22000:2018. Hal ini dikarenakan melalui sistem penilaian baldrige scoring, perusahaan dapat mengukur tingkatan pemenuhan klausul-klausul pada ISO 22000:2018 secara kuantitatif. Perancangan self assessment dilakukan agar perusahaan mampu memetakan permasalahan keamanan pangan yang terjadi dalam perusahaan serta menjadi pedoman bagi perusahaan untuk melakukan langkah-langkah perbaikan di masa depan, sehingga 
perbaikan secara terus menerus (continuous improvement) dapat terwujud dalam perusahaan. Pelaksanaan self assessment diharapkan dapat menjadi dasar audit internal bagi PT X untuk mendukung terwujudnya penerapan ISO 22000:2018. PT X juga dapat selalu meningkatkan mutu dari bahan pangan yang diproduksi serta kepuasan pelanggan dengan diterapkannya ISO 22000:2018.

\section{DAFTAR PUSTAKA}

Borda, D., Mihalache, O. A., Dumitraşcu, L., Gafițianu, D., \&amp; Nicolau, A. I. (2021). Romanian consumers' food safety knowledge, awareness on CERTIFIED labelled food and trust in information sources. Food Control, 120, 107544. https://doi.org/10.1016/j.foodcont.2020.107544

Gasperz, V. (n.d.). (2002). ISO 9001:200, MBNQA, dan HACCP. PT. Gramedia Pustaka Utama

Holt, G. (420). (2000). Exploring incentives of food safety controls: HACCP implementation in the UK dairy sector. Review of Agricultural Economics.

Indonesian Quality Award Foundation. (2013). Kriteria Kinerja Ekselen (Malcolm Baldrige Criteria for Performance Excellence) 2013-2014 Bidang Bisnis. Indonesian Quality Award Foundation. Jakarta.

ISO 22000:2018. (2021). Retrieved 14 October 2021, from https://www.iso.org/standard/65464.html

Jin, S., Zhou, J., \&amp; Ye, J. (2008). Adoption of HACCP system in the Chinese food industry: A comparative analysis. Food Control, 19(8), 823-828. https://doi.org/10.1016/j.foodcont.2008.01.008

Mengenal 4 Elemen Utama ISO 22000:2018. Indonesia Environment \&amp; Energy Center. (2020, July 30). Retrieved September 28, 2021, from https:/environment-indonesia.com/mengenal-iso-220002018/.

Singh, M. K. (2015). A study on IMPLEMENTING food safety management system in bottling plant. Procedia - Social and Behavioral Sciences, 189, 433-441. https://doi.org/10.1016/j.sbspro.2015.03.19

Tillema, H. (2010). Formative assessment in teacher education and teacher professional development. International Encyclopedia of Education, 563-571. https://doi.org/10.1016/b978-0-08-044894-7.016390 